\title{
L- and DL-carnitine induce tetanic fade in rat neuromuscular preparation
}

G. Lopes ${ }^{2}$ R.B. Bazotte ${ }^{1}$ R. Curi ${ }^{2}$ and W. Alves-Do-Prado ${ }^{1}$

\author{
${ }^{1}$ Departamento de Farmácia e Farmacologia, \\ Universidade Estadual de Maringá, Maringá, PR, Brasil \\ ${ }^{2}$ Departamento de Fisiologia e Biofísica, \\ Instituto de Ciências Biomédicas, Universidade de São Paulo, \\ São Paulo, SP, Brasil
}

\author{
Correspondence \\ W. Alves-Do-Prado \\ Laboratório de Farmacologia da \\ Transmissão Neuromuscular \\ DFF, UEM \\ Av. Colombo, 5790 \\ 87020-900 Maringá, PR \\ Brasil \\ Fax: +55-44-225-3863 \\ E-mail: alvesprado@wnet.com.br or \\ waprado@dff.uem.br \\ Research supported by CNPq (No. \\ 521727/96). \\ Publication supported by FAPESP.
}

Received January 3, 2002

Accepted June 24, 2003

\begin{abstract}
Carnitine, a structurally choline-like metabolite, has been used to increase athletic performance, although its effects on neuromuscular transmission have not been investigated. It is present in skeletal muscle and its plasma levels are about 30 to $90 \mu \mathrm{M}$. Using rat phrenic nerve diaphragm preparations indirectly and directly stimulated with high rate pulses, D-carnitine (30 and $60 \mu \mathrm{M})$, L-carnitine $(60 \mu \mathrm{M})$ and DL-carnitine $(60 \mu \mathrm{M})$ were shown to induce tetanic fade (D-carnitine $=19.7 \pm 3.1 \%, \mathrm{~N}=6$; L-carnitine $=16.6 \pm 2.4 \%, \mathrm{~N}=6$; DL-carnitine $=14.9 \pm 2.1 \%, \mathrm{~N}=6$ ) without any reduction of maximal tetanic tension. D-carnitine induced tetanic fade in neuromuscular preparations previously paralyzed with $d$-tubocurarine and directly stimulated. The effect was greater than that obtained by indirect muscle stimulation. Furthermore, previous addition of atropine (20 to $80 \mu \mathrm{M})$ to the bath did not reduce carnitine isomer-induced tetanic fade. In contrast to D-carnitine, the tetanic fade induced by L- and DLcarnitine was antagonized by choline $(60 \mu \mathrm{M})$. The combined effect of carnitine isomers and hemicholinium-3 $(0.01 \mathrm{nM})$ was similar to the effect of hemicholinium-3 alone. The data suggest that L- and DLcarnitine-induced tetanic fade seems to depend on their transport into the motor nerve terminal.
\end{abstract}

Key words - Carnitine

- Skeletal muscle

- Tetanic fade

- Atropine

\section{Introduction}

Carnitine is a quaternary amine (3-OH-4N-trimethyl-aminobutyric acid) synthesized in the human body from lysine and methionine $(1,2)$. Although carnitine is endogenously produced in the brain, kidney and liver, it may also be found in milk, fish, eggs and meat (3-8). Carnitine is also found in skeletal muscle and in the heart, but its presence in these tissues depends on blood flow (9). The normal plasma concentration of car- nitine in humans ranges from 30 to $90 \mu \mathrm{M}$, being $10-15 \%$ as acylcarnitine and $85-90 \%$ free (10). Since it is an important metabolic substance, carnitine facilitates burning of fatty acids as well as the mitochondrial transport of long-chain fatty acids, which, in turn, are important for $\beta$-oxidation (11-13). Carnitine is structurally similar to choline, a substrate for acetylcholine synthesis $(14,15)$, and has been used as a supplemental agent to increase performance in cardiovascular and renal diseases $(16,17)$ and in lipid storage 
myopathies associated with muscle fatigue and low carnitine content in skeletal muscle (18-20). Carnitine is found in L- and Disomeric forms, but only its L-isomeric form has been described as active (5-10). Although inactive, D-carnitine may competitively inhibit the utilization of L-carnitine by different tissues (1).

Acetylcholine, in addition to acting on subsynaptic membranes, also stimulates nicotinic and muscarinic presynaptic receptors increasing or reducing its own output, respectively (21-23). When the motor nerve is stimulated at high frequency rates $(>100$ $\mathrm{Hz}$ ), contraction is not sustained and produces a characteristic myographic record called fade of transmission, tetanic fade or Wedensky inhibition (24). This effect is also observed at frequencies lower than $100 \mathrm{~Hz}$ when the neuromuscular preparations are pretreated with anticholinesterase or antinicotinic agents $(21,23)$. Drug-induced tetanic fade may be produced by activation of presynaptic muscarinic receptors, since atropine antagonizes the tetanic fade induced by anticholinesterase or antinicotinic agents (23). On the other hand, reduction in maximal tetanic tension not followed by tetanic fade is obtained in preparations indirectly stimulated when drugs block the postsynaptic nicotinic receptors $(21,23)$.

It has been recently proposed that carnitine might be useful to increase athletic performance (25-27), but its effects on neuromuscular transmission have not been investigated. Since skeletal muscle contains high levels of carnitine (28), and the latter is structurally similar to choline, the present research was undertaken to determine the effects of carnitine on neuromuscular transmission in rats.

\section{Material and Methods}

\section{Neuromuscular preparation}

Phrenic nerve and diaphragm muscle were isolated from male Wistar rats (200-250 g) and assembled according to the method of Bülbring (29). Each muscle was immersed in a 30-ml chamber containing Krebs buffer: $188 \mu \mathrm{M} \mathrm{NaCl}, 47 \mu \mathrm{M} \mathrm{KCl}, 1.9 \mu \mathrm{M} \mathrm{CaCl}_{2}$, $1.2 \mu \mathrm{M} \mathrm{MgSO}_{4}, 25 \mu \mathrm{M} \mathrm{NaHCO} 3,1.2 \mu \mathrm{M}$ $\mathrm{KH}_{2} \mathrm{PO}_{4}$, and $11 \mu \mathrm{M}$ glucose, at $37^{\circ} \mathrm{C}$ and continuously aerated with a mixture of oxygen $(95 \%)$ and carbon dioxide $(5 \%)$. The phrenic nerve was stimulated with a bipolar platinum electrode applying a supramaximal rectangular pulse $(0.2 \mathrm{~Hz}, 0.05 \mathrm{~ms})$. Muscle contractions were recorded with an Ugo Basile polygraph.

\section{Experimental design and data analysis}

In some experiments the standard rate of stimulation was $0.2 \mathrm{~Hz}$. However, stimulation at a higher rate (tetanic) was also applied to the nerve for $10 \mathrm{~s}$ at 10 -min intervals. The tension produced at the beginning of tetanic stimulation (A) was compared with that obtained at the end of tetanic stimulation (B) (Figure 1). The stimulation rate (F) $(180-200 \mathrm{~Hz})$ required to obtain a 0.50 ratio ( $\mathrm{R}=\mathrm{B} / \mathrm{A}$ ) was determined for each preparation, and $F / 2$ was used throughout the experiments. L-carnitine, DL-carnitine, D-carnitine, or hemicholinium-3 (2,2'-\{4,4'-biphenylene $\}$-bis-\{2-hydroxy-4,4-dimethylmorpholinium bromide $\}$ ) was then added to the organ bath, and $\mathrm{F} / 2$ was repeated at $\mathrm{t}=10$, 20, 30, 40, 50 and $60 \mathrm{~min}$. The nutrient solution in the bath was replaced with drugfree Krebs buffer (four times) at $\mathrm{t}=60$, and the R-ratio was recorded at $\mathrm{t}=70$ and 80 min. The same sequence was repeated with atropine or choline, which was added $10 \mathrm{~min}$ prior to L-, DL-, or D-carnitine. The R-ratio obtained after drug addition was calculated as the percentage of that observed before drug administration. The lowest concentration of each agent was determined and added to the bath.

The unpaired Student $t$-test was used for comparison of the data, with the level of 


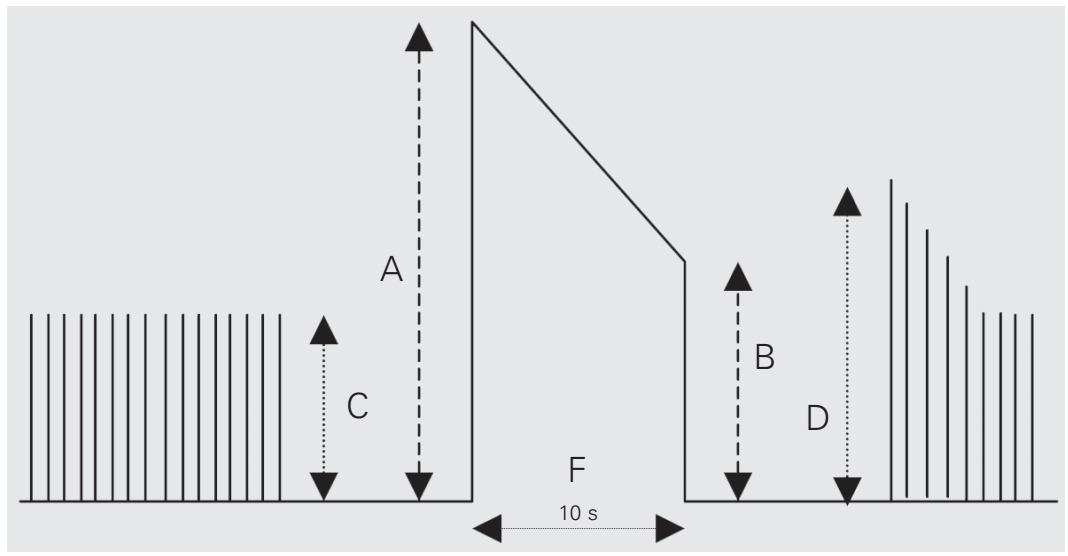

significance set at $\mathrm{P}<0.05$. A similar experimental design was used with directly stimulated neuromuscular preparations (previously paralyzed with $d$-tubocurarine).

\section{Drugs}

The following drugs were used: L-carnitine hydrochloride, DL-carnitine hydrochloride, D-carnitine hydrochloride, atropine sulfate, hemicholinium-3 bromide, $d$-tubocurarine chloride, and choline bromide (Sigma, St. Louis, MO, USA).

\section{Results}

L-carnitine $(60 \mu \mathrm{M})$, DL-carnitine $(60$ $\mu \mathrm{M})$ and D-carnitine $(30 \mu \mathrm{M})$ produced Wedensky inhibition in preparations indirectly stimulated with 90 - to $100-\mathrm{Hz}$ rectangular pulses. These were the lowest concentrations that induced reduction of $\mathrm{R}$-values (Figure 2A, B and C). Concentrations higher than those studied induced higher tetanic fade (data not shown), although they were higher than any physiological concentration (10). R-value reduction induced by $60 \mu \mathrm{M}$ L-carnitine, $60 \mu \mathrm{M}$ DL-carnitine and $30 \mu \mathrm{M}$ D-carnitine was observed 10 min after drug administration and remained below control levels up to $40 \mathrm{~min}$ before the nutrient solution was replaced with drug-free Krebs buffer (Figure 2A, B and C). Although R-value reduction by $60 \mu \mathrm{M}$ D-carnitine was re-
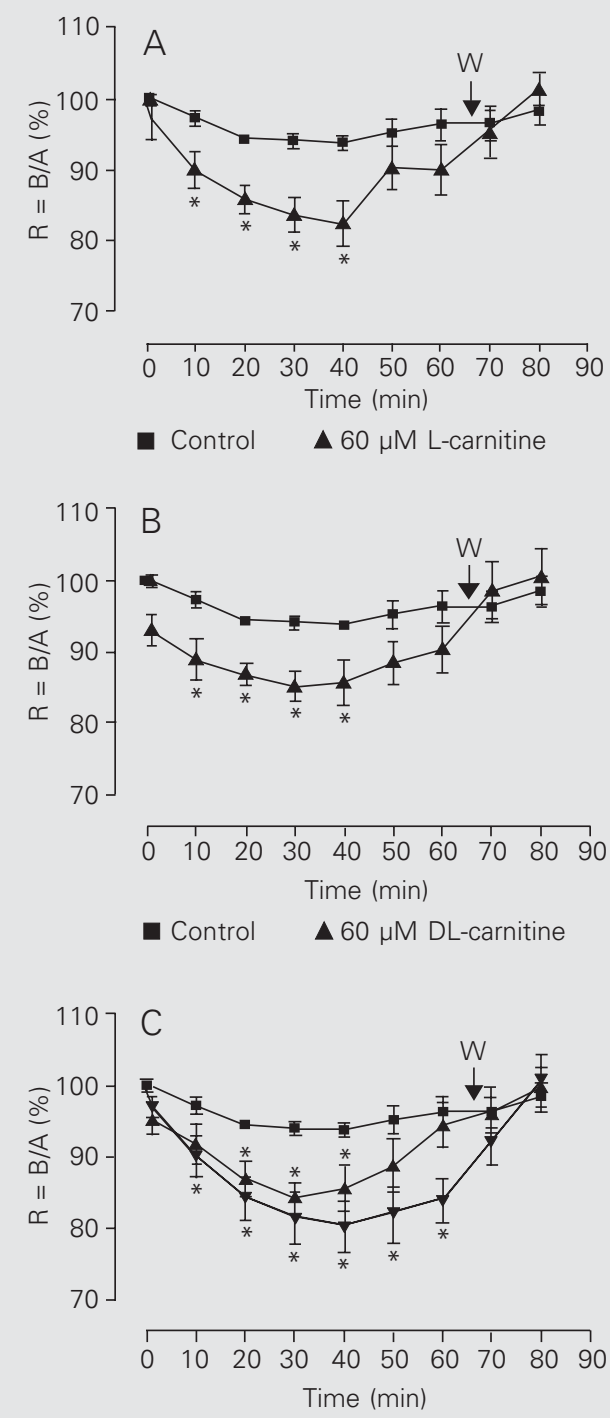

- Control $\Delta 30 \mu \mathrm{M}$ D-carnitine

$\boldsymbol{} 60 \mu \mathrm{M}$ D-carnitine

Figure 1. Representation of the contractile responses of rat skeletal muscle during tetanic stimulation. Tetanic fade is the ratio $(R)$ between the tension at the end $(B)$ and the tension at the beginning $(A)$ of the tetanic response $(\mathrm{R}=\mathrm{B} / \mathrm{A})$. $C$ and $D$ correspond to pre-tetanic and post-tetanic twitches, respectively. $F$ indicates the stimulation rate required to obtain $\mathrm{R}=$ 0.5

Figure 2. Percentage of reduction in R-values induced by $\mathrm{L}$ carnitine (A), DL-carnitine (B) and D-carnitine $(C), 30$ and 60 $\mu \mathrm{M}$, in indirectly stimulated neuromuscular preparations. The Rratio is reported on the ordinate as percent of that obtained in drug-free Krebs buffer, taken as $100 \%(t=0)$. The drugs were added at $\mathrm{t}=0$. W indicates replacement of drug-free Krebs buffer (four times). Each point represents the mean \pm SEM of 6 experiments. ${ }^{*} \mathrm{P}<0.05 \mathrm{com}-$ pared to control (Student $t$-test). 
Figure 3. Percent reduction of R-values induced by L-carnitine, DL-carnitine and D-carnitine, 30 and $60 \mu \mathrm{M}$, in neuromuscular preparations previously paralyzed with $d$-tubocurarine and stimulated directly. The R-ratio is reported on the ordinate as percent of that obtained in drugfree Krebs buffer, taken as $100 \%(t=0)$. The drugs were added at $\mathrm{t}=0$. Each point represents the mean \pm SEM of 6 experiments. ${ }^{*} P<0.05$ compared to L- and DL-carnitine (Student $t$-test).

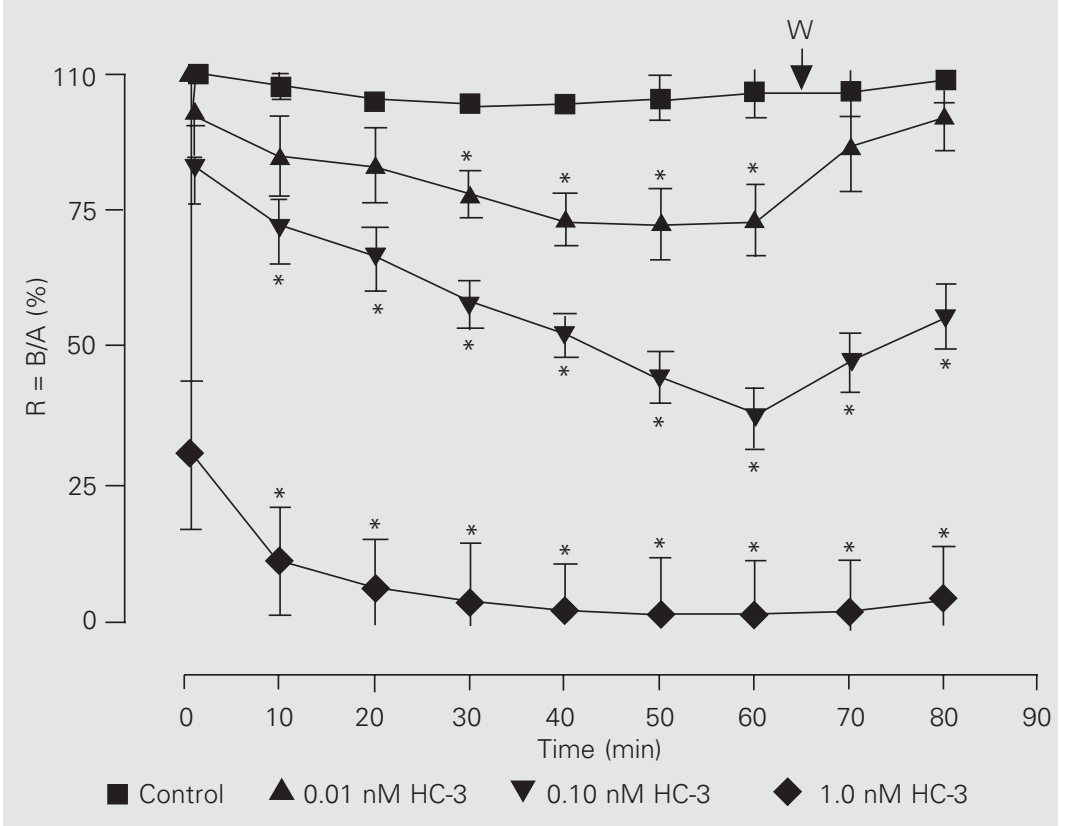

Figure 4. Percent reduction in R-values induced by hemicholinium-3 (HC-3) in indirectly stimulated neuromuscular preparations of rats. The R-ratio is reported on the ordinate as percent of that obtained in drug-free Krebs buffer, taken as $100 \%(t=0)$. The drugs were added at $t=0$. $W$ indicates replacement of drug-free Krebs buffer (four times). Each point represents the mean \pm SEM of 6 experiments. ${ }^{*} P<0.05$ compared to control (Student $t$ test). corded 10 min after drug administration, it remained below control levels until the nutrient solution was replaced with drug-free Krebs buffer (Figure 2C). The same drugs did not decrease maximal tetanic tension (A component of R) when compared to control (data not shown).

$\mathrm{R}$-values for L-carnitine and $60 \mu \mathrm{M}$ DLcarnitine did not differ from control values in neuromuscular preparations previously

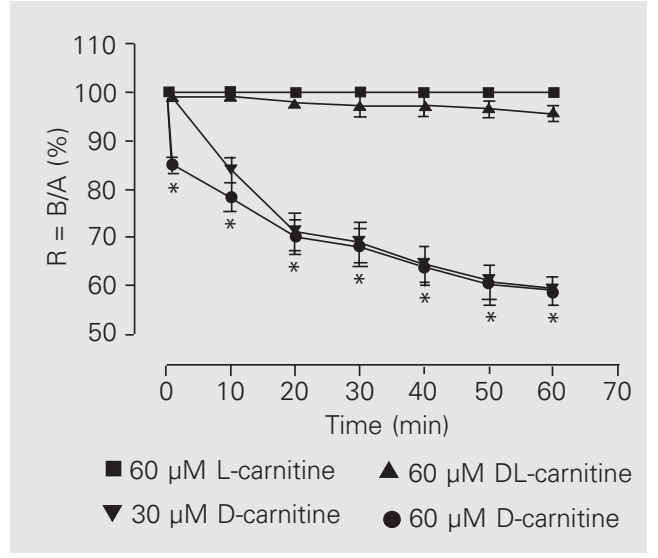

paralyzed with $d$-tubocurarine and directly stimulated. On the other hand, 30 and $60 \mu \mathrm{M}$ $\mathrm{D}$-carnitine showed different $\mathrm{R}$-values compared to control in the same protocol (Figure 3).

Atropine $(20,40$ or $80 \mu \mathrm{M})$ added $10 \mathrm{~min}$ prior to $60 \mu \mathrm{M}$ L-carnitine, $60 \mu \mathrm{M}$ DLcarnitine, or $30 \mu \mathrm{M}$ D-carnitine did not antagonize the effects of L-, DL- or D-carnitine (data not shown).

Hemicholinium-3 (0.01-1 nM) produced a dose-dependent tetanic fade in indirectly stimulated preparations and $10 \mathrm{pM}$ hemicholinium-3 was the lowest concentration studied that reduced R-values (Figure 4). Hemicholinium-3-induced R-value reduction was observed 10 min after drug administration and remained below control levels until the nutrient solution was replaced with drugfree Krebs buffer (Figure 4). Hemicholinium-3 did not decrease maximal tetanic tension (A component of $\mathrm{R}$ ) when compared to control (data not shown).

The combined effect of L-carnitine, DLcarnitine or D-carnitine with hemicholinium3 was investigated. No synergistic effect was observed for combinations of these drugs. The combined effects were similar to the effect of hemicholinium-3 alone (Figure 5A, $\mathrm{B}, \mathrm{C}$ and D).

The effects induced by $60 \mu \mathrm{M}$ L-carnitine or $60 \mu \mathrm{M}$ DL-carnitine were antagonized by the previous addition of $60 \mu \mathrm{M}$ choline to the bath (Figure 6). Similarly, although $120 \mu \mathrm{M}$ choline was added to the bath, the effect of D-carnitine was not antagonized by choline (Figure 6).

\section{Discussion}

L-carnitine $(60 \mu \mathrm{M})$ and DL-carnitine $(60 \mu \mathrm{M})$ reduced $\mathrm{R}$-values (tetanic fade), but this effect was not followed by a reduction of maximal tetanic tension when preparations were stimulated indirectly at $100 \mathrm{~Hz}$. The same agents did not produce any change in $\mathrm{R}$-values when the preparations, previously 

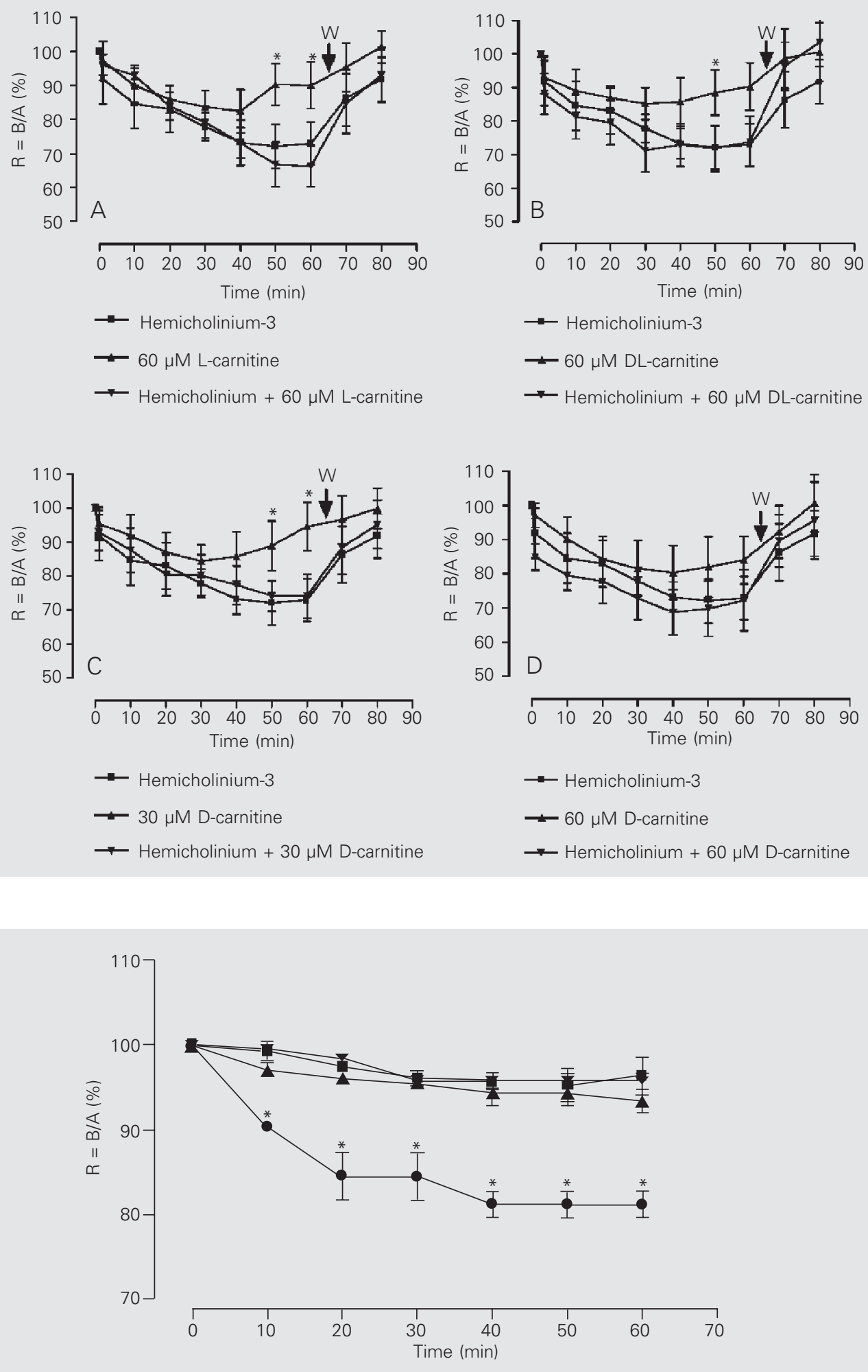

Control

А $60 \mu \mathrm{M}$ choline + $60 \mu \mathrm{M}$ L-carnitine
V $60 \mu \mathrm{M}$ choline + $60 \mu \mathrm{M}$ DL-carnitine
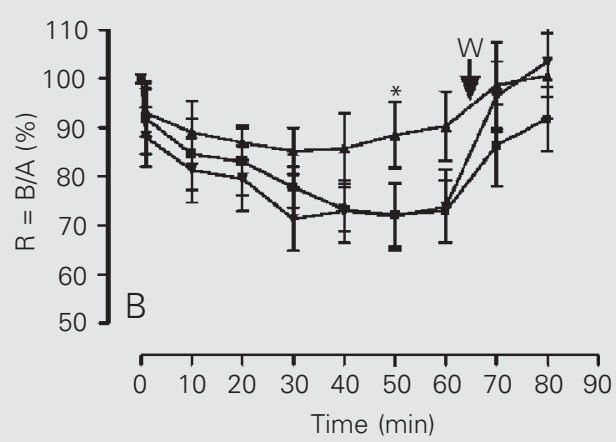

$\rightarrow$ Hemicholinium-3

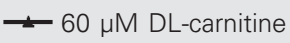

$\rightarrow$ Hemicholinium + $60 \mu \mathrm{M}$ DL-carnitine
- $120 \mu \mathrm{M}$ choline + $60 \mu \mathrm{M}$ D-carnitine
Figure 5. Percent reduction in R-values induced by $60 \mu \mathrm{M} \mathrm{L-}$ carnitine and/or hemicholinium3 (A), $60 \mu \mathrm{M}$ DL-carnitine and/or hemicholinium-3 (B) and $30 \mu \mathrm{M}$ D-carnitine and/or hemicholinium-3 (C), and $60 \mu \mathrm{M}$ D-carnitine and/or hemicholinium-3 (D), in indirectly stimulated neuromuscular preparations. The Rratio is reported on the ordinate as percent of that obtained in drug-free Krebs buffer, taken as $100 \%(t=0)$. The drugs were added at $\mathrm{t}=0$. W indicates replacement of drug-free Krebs buffer (four times). Each point represents the mean \pm SEM of 5 experiments. ${ }^{*} \mathrm{P}<0.05 \mathrm{com}-$ pared to control (Student $t$-test).

Figure 6. Percent reduction in $\mathrm{R}$ values induced by choline and Lcarnitine $(\mathrm{LC})$, choline and $\mathrm{DL}$ carnitine (DLC), and choline and $D$-carnitine (DC) in indirectly stimulated neuromuscular preparations. The R-ratio is reported on the ordinate as percent of that obtained in drug-free Krebs buffer, taken as 100\% ( $\mathrm{t}=0$ ). Choline was added 10 min before the addition of LC, DLC or DC. LC, DLC and DC were added at $t=0$. Each point represents the mean \pm SEM of 4 experiments. ${ }^{*} P<0.05$ compared to control (Student $t$-test). 
paralyzed with $d$-tubocurarine, were stimulated directly. These results indicate that tetanic fade induced by L- and DL-carnitine has its origin at the presynaptic level since a reduction in maximal tetanic tension is obtained when drugs block the postsynaptic nicotinic receptors $(21,23)$. On the other hand, 30 and $60 \mu \mathrm{M}$ D-carnitine reduced R-values without reducing maximal tetanic tension when the preparations were directly or indirectly stimulated. Therefore, the tetanic fade induced by D-carnitine seems to depend on its action on skeletal muscle. In contrast, it was also observed that the effects induced by D-carnitine were lower in the experiments performed with indirect muscle stimulation. The data suggest that D-carnitine acting at the presynaptic level was able to reduce the action of D-carnitine on skeletal muscle. The possibility that tetanic fade induced by D-carnitine in indirectly stimulated preparations arises from an action on postsynaptic nicotinic receptors seems unlikely because no reduction of maximal tetanic tension was recorded $(21,23)$.

$\mathrm{R}$-value reduction induced by $60 \mu \mathrm{M}$ Lcarnitine, $60 \mu \mathrm{M} \mathrm{DL}$-carnitine and $30 \mu \mathrm{M} \mathrm{D}$ carnitine in indirectly stimulated preparations was observed 10 min after drug administration and remained below control levels until 40 min before the nutrient solution was replaced with drug-free Krebs buffer. In contrast, R-value reduction by $60 \mu \mathrm{M}$ D-carnitine was also observed $10 \mathrm{~min}$ after drug administration in indirectly stimulated preparations. However, it remained below control levels until the nutrient solution was replaced with drug-free Krebs buffer. R-value reduction induced by $60 \mu \mathrm{M}$ D-carnitine appeared earlier $(\mathrm{t}=1 \mathrm{~min})$ when preparations were stimulated directly. Therefore, the difference observed with indirect muscle stimulation might depend on a longer duration of enzymatic blockade induced by $60 \mu \mathrm{M}$ Dcarnitine in skeletal muscle, since D-carnitine has been reported to block carnitine acetyltransferase activity in muscle, thereby reducing the burning of fatty acids as well as the mitochondrial transport of long-chain fatty acids (11-13).

Previous administration of 20 to $80 \mu \mathrm{M}$ atropine, an antimuscarinic agent (30), did not antagonize the effects induced by Lcarnitine, DL-carnitine or D-carnitine. Such results indicate that the reduction in R-values induced by different forms of carnitine was not produced by interaction with inhibitory presynaptic muscarinic receptors since stimulation of such receptors induces tetanic fade (23).

In contrast, studies with hemicholinium-3 showed that the agent, as well as L-, DL- and $\mathrm{D}$-carnitine, reduced R-values without any reduction of maximal tetanic tension in indirectly stimulated preparations. The effect of hemicholinium was dose dependent, indicating that choline uptake was not completely inhibited by $0.01 \mathrm{nM}$ hemicholinium-3. If Land DL-carnitine reduced transport of choline acting at different sites or at sites similar to those blocked by hemicholinium, a synergistic effect would have been expected when the experiments were performed with a combination of $0.01 \mathrm{nM}$ hemicholinium and Lor DL-carnitine. However, such synergism was not observed, suggesting that the effects recorded with L- and DL-carnitine might depend on transport of L- and DL-carnitine into the nerve. This hypothesis is supported by results indicating that carnitine is soluble in water and its transport across the cell membrane via passive diffusion is unlikely (31). Therefore, since carnitine is structurally similar to choline $(14,15)$ it is possible that the antagonism recorded in the experiments with choline probably occurred in the nerve and that the tetanic fade induced by Land DL-carnitine was produced by competition with endogenous choline, thereby reducing the synthesis of acetylcholine by choline acetyltranferase. It is also possible to hypothesize that the addition of choline to the bath also reduced the neuronal transport of L- and DL-carnitine since the tetanic fade 
produced by such agents was abolished by previous addition of choline to the bath. The transport of L- and DL-carnitine into the motor nerve terminal might be produced by interaction of carnitine isomers at sites different from those used by choline since the choline transporter has sites with high and low affinity for choline (32). Furthermore, the tetanic fade induced by D-carnitine was not modified by previous treatment of the preparations with choline, suggesting that the presynaptic action of D-carnitine might be determined by mechanisms other than those suggested for L- and DL-carnitine. However, it is possible to propose that the presynaptic effects of D-carnitine also depended on its neuronal uptake since the effects induced by hemicholinium alone were not different from those recorded in association with D-carnitine.

The literature demonstrates that only Lcarnitine is active (5-10), but D-carnitine may competitively inhibit the utilization of L-carnitine by different tissues (1). This interaction might have occurred since the tetanic fades induced by L-carnitine and DLcarnitine were similar and since it has been shown that in skeletal muscle cells the $K_{\mathrm{m}}$ value for L-carnitine uptake is higher than when D-carnitine is administered in combi- nation (9). On the other hand, the muscular effects induced by the D-isomer might be produced by a reduction in cellular metabolism since this agent competitively inhibits the carnitine acetyltransferase activity, thereby reducing the burning of fatty acids as well as the mitochondrial transport of longchain fatty acids (11-13).

Taken together, the present results suggest that tetanic fade induced by L- and DLcarnitine depends on the transport of L-carnitine into the motor nerve terminal, reducing the synthesis of acetylcholine by probable competition with endogenous choline. Besides, the tetanic fade induced by D-carnitine might also depend on D-carnitine transport into the terminal, but the presynaptic action of the agent may be different from those hypothesized for it. Since different carnitine isomers reduced the neuromuscular transmission, caution is recommended for their use in the treatment of neurological disorders and/or as agents for enhancing athletic performance.

\section{Acknowledgments}

We are grateful to Mrs. I.L. Santos for technical support and to Prof. Dr. L.R.G. Britto for kindly supplying hemicholinium.

\section{References}

1. Leibovitz B \& Mueller J (1993). Carnitine. Journal of Optimal Nutrition, 2: 90-109.

2. Bieber LL (1988). Carnitine. Annual Review of Biochemistry, 57: 261-283.

3. Leibovitz B (1984). Carnitine - The Vitamin Bt Phenomenon. Dell Publishing Company, New York.

4. Rebouche C \& Engel A (1980). Tissue distribution of carnitine biosynthetic enzymes in man. Biochimica et Biophysica Acta, 630: 2229 .

5. Rebouche CJ (1980). Comparative aspects of carnitine biosynthesis in microorganisms and mammals with attention to carnitine biosynthesis in man. In: Fraenkel RA \& McGarry J (Editors), D-Carnitine Biosynthesis, Metabolism, and Functions. Academic Press, Inc., New York, 57-72.

6. Broquist HP \& Borum PR (1982). Carnitine biosynthesis. Nutritional implications. Advances in Nutritional Research, 4: 181-204.

7. Borum P (1983). Carnitine. Annual Review of Nutrition, 3: 233-259.
8. Rebouche CJ (1986). Recent advances in carnitine biosynthesis and transport. In: Borum P (Editor), Clinical Aspects of Human Carnitine Deficiency. Pergamon Press, New York, 1-15.

9. Bremer J (1983). Carnitine - metabolism and functions. Physiological Reviews, 63: 1420-1480.

10. Bazilinski N \& Dunea G (1990). Carnitine: an overview. International Journal of Artificial Organs, 13: 720-722.

11. Pahl MV, Varizi ND \& Seo M (1990). Intestinal absorption of carnitine in experimental azotemia. Research Communications in Chemical Pathology and Pharmacology, 70: 337-347.

12. Kuwajima M, Kono N, Horiuchi M et al. (1991). Animal model of systemic carnitine deficiency: analysis in $\mathrm{C} 3 \mathrm{H}-\mathrm{H}-2$ strain of mouse associated with juvenile visceral steatosis. Biochemical and Biophysical Research Communications, 174: 1090-1094.

13. Visentin M, Bellasio R \& Tacconi MT (1995). Reye syndrome model in rats: protection against liver abnormalities by L-carnitine and acetyl-L-carnitine. Journal of Pharmacology and Experimental Thera- 
peutics, 275: 1069-1075.

14. Dallemagne MJ, Philippot E, Binon F \& Dumoulin EL (1955). Modes of action of carnitine and its derivatives on the motor-end-plates and ganglionic synapses of the rat. In: International Anesthesia Research Society, Proceedings of the World Congress of Anesthesiologists. Burgess Publishing Company, Minneapolis, MI, USA, 285287.

15. Blum K, Seifter E \& Seifter J (1971). The pharmacology of D- and Lcarnitine and D- and L-acetylcarnitine: comparison with choline and acetylcholine. Journal of Pharmacology and Experimental Therapeutics, 178: 331-338.

16. Suzuki M, Kanaya M \& Muramatsu S (1976). Effects of carnitine administration, fasting, and exercise on urinary carnitine excretion in man. Journal of Nutritional Science and Vitaminology, 22: 169174.

17. Lennon D, Stratman F \& Shrago E (1982). The effects of exercise training on carnitine status and physical work capacity in dialysis patients. Medicine and Science in Sports and Exercise, 14: 165 (Abstract)

18. Campos Y, Huertas R, Lorenzo G, Bautista J, Gutierrez E, Aparicio M, Alesso L \& Arenas J (1993). Plasma carnitine insufficiency and effectiveness of L-carnitine therapy in patients with mitochondrial myopathy. Muscle and Nerve, 16: 150-153.

19. Campos $Y$, Huertas R, Bautista J et al. (1993). Muscle carnitine deficiency and lipid storage myopathy in patients with mitochondrial myopathy. Muscle and Nerve, 16: 778-781.

20. Arenas J, Gonzalez-Crespo MR, Campos Y, Martin MA, Cabello A \& Gomez-Reino JJ (1996). Abnormal carnitine distribution in the muscles of patients with idiopathic inflammatory myopathy. Arthritis and Rheumatism, 39: 1869-1874.

21. Bowman WC (1980). Prejunctional and postjunctional cholinoceptors at the neuromuscular junction. Anesthesia and Analgesia, 59: 935-943.

22. Wessler I (1992). Acetylcholine at motor nerves: storage, release, and presynaptic modulation by autoreceptors and adrenoreceptors.
International Review of Neurobiology, 34: 283-384

23. Alves-do-Prado W, Corrado AP \& Prado WA (1987). Reversal by atropine of tetanic fade induced in cats by antinicotinic and anticholinesterase agents. Anesthesia and Analgesia, 66: 492-496.

24. Rosemblueth A \& Morison RS (1937). Curarization, fatigue and Wedensky inhibition. American Journal of Physiology, 119: 236256.

25. Lennon D, Stratman F \& Shrago E (1983). Effects of acute moderate-intensity exercise on carnitine metabolism in men and women. Journal of Applied Physiology, 55: 489-495.

26. Marconi C, Sassi G \& Carpinelli A (1985). Effects of L-carnitine loading on the aerobic and anaerobic performance of endurance athletes. European Journal of Applied Physiology, 54: 131-135.

27. Gorostiaga E, Maurer C \& Eclache J (1989). Decrease in respiratory quotient during exercise following L-carnitine supplementation. International Journal of Sports Medicine, 10: 169-174

28. Angelini C, Vergani L \& Costa G (1986). Clinical study of efficacy of $\mathrm{L}$-carnitine and metabolic observations in exercise physiology. In: Borum P (Editor), Clinical Aspects of Human Carnitine Deficiency. Pergamon Press, New York, 38.

29. Bülbring $E$ (1946). Observations on the isolated phrenic nerve diaphragm preparation of the rat. British Journal of Pharmacology, 1: 38-61.

30. Brown JH \& Taylor P (1996). Muscarinic receptor agonists and antagonists. In: Hardman JG, Gilman AG \& Limbird LE (Editors), The Pharmacological Basis of Therapeutics. 9th edn. McGraw-Hill, New York.

31. Tamai I, Ohashi R, Nezu J, Sai Y, Kobayashi D, Oku A, Shimane M \& Tsuji A (2000). Molecular and functional characterization of organic cation/carnitine transporter family in mice. Journal of Biological Chemistry, 275: 40064-40072.

32. Rylett RJ \& Colhoun EH (1984). An evolution of irreversible inhibition of synaptosomal high-affinity choline transport by choline mustard aziridinium ion. Journal of Neurochemistry, 43: 787-794. 